\title{
Copper (II) Remediation Using Novel Ironphosphate Nanoparticles
}

\author{
Nadia Adam ${ }^{1}$, Sergei Rouvimov ${ }^{2}$, Justin Gates ${ }^{3}$, Bethany Beachel ${ }^{3}$ \\ 1. Department of Geology \& Geophysics, University of Wyoming, Laramie, WY, USA \\ 2. Notre Dame Integrated Imaging Facility, University of Notre Dame, Notre Dame, IN, 46556, USA \\ 3. Department of Biology, East Central University, Ada, OK, USA
}

Soils at current or previously mined and smelter sites normally contain higher concentrations of heavy metals such as $\mathrm{Pb}, \mathrm{Cu}, \mathrm{Cd}$, and $\mathrm{Hg}$ exceeding the current regulatory levels [1]. Engineered nanoparticles have been found to offer great promise for remediation of contaminated soils and groundwater [2]. General mechanisms of remediation using engineered nanoparticles are induction of various sorption processes (e.g., adsorption to $\mathrm{Fe}_{2} \mathrm{O}_{3}$ nanoparticles), reductive immobilization (e.g., EZVI for reduction of chlorinated solvents), or surface precipitation of new contaminant phases with much reduced mobility such as $\mathrm{Pb}$ immobilization via addition of apatite resulting in precipitation of recalcitrant pyromorphite $[3,4]$. Phosphate can effectively capture metal cations including those of heavy metal contaminants, and phosphatemetal precipitates are typically very stable over a wide range of environmental conditions [4]. Therefore, metalphosphate nanoparticles hold promise for effective remediation of contaminated sites. Our main objective was to characterize copper remediation using ironphosphate nanoparticles in the presence of common soil ligands using transmission electron microscopy and energy dispersive xray analysis.

An understanding of metal transformation processes and their kinetics using 'direct' solid state speciation is lacking and is critical to accurately predict contaminant stabilization. Nanoparticle dissolution and the stability of heavy metalphosphate phases can be affected by $\mathrm{pH}$, their size and by the presence of common soil ligands such as metal chelating (siderophores, e.g., Desferrioxamine B) and phosphorus solubilizing ligands such as carboxylate based organic acid anions [5,6]. Here, nitrate salt of copper was added to $\mathrm{pH}$ adjusted (6.0) fixed suspension volumes $(30 \mathrm{ml})$ containing $1.5 \mathrm{~g} / \mathrm{L}$ nanoparticles and $10 \mathrm{mM} \mathrm{KCl} \mathrm{FePO}_{4}$ nanoparticles while stirring at moderate speeds to have a starting concentration of $1 \mathrm{mM} \mathrm{Cu}(\mathrm{II})$ in the sample. The experiment was performed in duplicates and the samples were equilibrated on a reciprocating water bath shaker at $25^{\circ} \mathrm{C}$; sample aliquots were drawn at 24 , and $336 \mathrm{hrs}$ and centrifuged to remove the supernatants and refrigerated. Samples were prepared for TEM analysis by diluting the solid sample with supernatant and mounted on a holey carbon Ni coated grid. TEM data were collected on FEI Titan 80300 microscope equipped with 4kx4k Gatan CCD camera and energy dispersive xray spectrometer (Oxford Inca EDS, with spectral resolution of $\sim 130 \mathrm{eV})$. Gatan doubletilt Be holder has been used to avoid $\mathrm{Cu}$ signal that may arise from the holder.

Figures $1 \mathrm{a}$ and $1 \mathrm{~b}$ show TEM images of pristine ironphosphate nanoparticles. The TEM images showed $\sim 10 \mathrm{~nm}$ irregularly shaped particles with poorly defined boundaries. TEM data suggest that the nanoparticles are mostly amorphous (noncrystalline). The EDS results evidenced that the variation in 
the composition of nanoparticles are very small (Table 1). Figure 1b shows the TEM image of $\mathrm{Cu}$ (II) reacted iron-phosphate nanoparticles at 336 hrs. Since TEM images (compare e.g. Figs. 1b and 1b) did not indicate the formation of a new phase, the results are consistent with surface complexation of $\mathrm{Cu}$ (II) on iron-phosphate nanoparticles. In addition, the EDS results (Table 1) showed that $4 \pm 2 \% \mathrm{Cu}$ (II) was associated with the nanoparticles at $24 \mathrm{hr}$ and $336 \mathrm{hr}$ indicating that complexation of $\mathrm{Cu}(\mathrm{II})$ was stable and the nanoparticles show great potential for in-situ remediation of $\mathrm{Cu}$ (II) contaminated ground and surface waters.

\section{References:}

[1] Diawara et al., 2006.

[2] Karn et al., 2009

[3] Kumpiene et al., 2008;

[4] Knox et al., 2006.

[5] Scheckel and Ryan, 2002;

[6] Manecki and Maurice, 2008

[7] We acknowledge funding from the National Research Council of the National Academies, and support from Dr.Chunming Su of the EPA research office in Ada, OK.
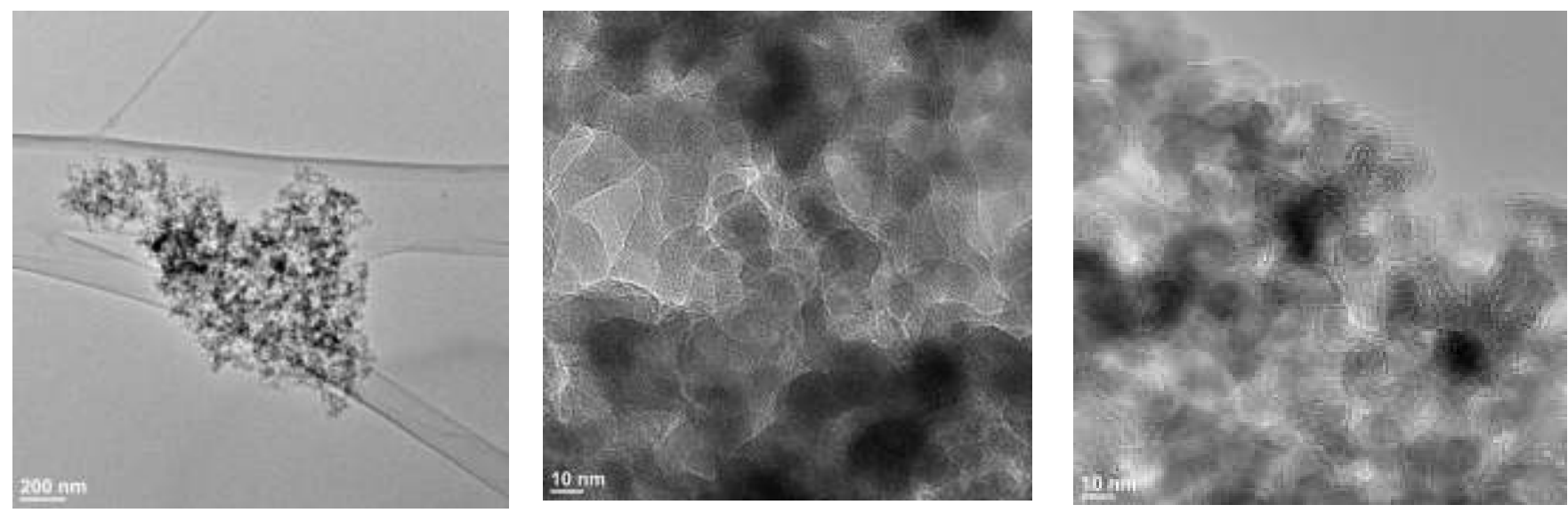

Figure 1. TEM images of pristine iron-phosphate nanoparticles $(a, b)$ and nanoparticles reacted with $\mathrm{Cu}(\mathrm{II})$ at $\mathrm{pH} 6$ in the presence of citrate and DFO-B.

\begin{tabular}{|c|c|c|c|}
\hline $\begin{array}{c}\text { Concentration } \\
(\%)\end{array}$ & Pristine nanoparticles & $\begin{array}{c}\text { Nanoparticles reacted } \\
\text { with } \mathrm{Cu}(\mathrm{II}) \text { at } 24 \mathrm{hr}\end{array}$ & $\begin{array}{c}\text { Nanoparticles reacted } \\
\text { with Cu(II) at 336 hr }\end{array}$ \\
\hline $\mathrm{P}$ & $51 \pm 3$ & $48.7 \pm 0.6$ & $48.7 \pm 0.6$ \\
\hline $\mathrm{Fe}$ & $49 \pm 3$ & $47.7 \pm 1.1$ & $47.7 \pm 1.1$ \\
\hline $\mathrm{Cu}$ & 0 & $4 \pm 2$ & $4 \pm 2$ \\
\hline
\end{tabular}

Table 1: Concentration of phosphate, iron, and copper in nanoparticles calculated from EDS results. Data from three points was averaged for each sample. 